\title{
Cancer association as a risk factor for anti-HMGCR antibody-positive myopathy \\ OPEN
}

Masato Kadoya, MD

Ayumi Hida, MD, PhD

Meiko Hashimoto

Maeda, MD, PhD

Kenichiro Taira, MD

Chiseko Ikenaga, MD

Naohiro Uchio, MD

Akatsuki Kubota, MD,

$\mathrm{PhD}$

Kenichi Kaida, MD, PhD

Yusuke Miwa, MD, PhD

Kazuhiro Kurasawa, MD,

$\mathrm{PhD}$

Hiroyuki Shimada, MD, $\mathrm{PhD}$

Masahiro Sonoo, MD, $\mathrm{PhD}$

Atsuro Chiba, MD, PhD

Yasushi Shiio, MD, PhD

Yoshikazu Uesaka, MD,

PhD

Yasuhisa Sakurai, MD,

$\mathrm{PhD}$

Toru Izumi, MD

Manami Inoue, MD,

$\mathrm{PhD}$

Shin Kwak, MD, PhD

Shoji Tsuji, MD, PhD

Jun Shimizu, MD, PhD

Correspondence to

Dr. Shimizu:

jshimizu-tky@umin.ac.jp

\section{Supplemental data} at Neurology.org/nn

\section{ABSTRACT}

Objective: To show cancer association is a risk factor other than statin exposure for anti-3hydroxy-3-methylglutaryl coenzyme A reductase autoantibody-positive (anti-HMGCR Ab+) myopathy.

Methods: We analyzed the clinical features and courses of 33 patients (23 female and 10 male) with anti-HMGCR Ab + myopathy among 621 consecutive patients with idiopathic inflammatory myopathies.

Results: Among the 33 patients, 7 (21\%) were statin-exposed and 26 were statin-naive. In relation with cancer, there were 12 patients (statin-exposed, $n=4$ ) with cancers detected within 3 years of myopathy diagnosis (cancer association), 3 patients (all statin-naive) with cancers detected more than 3 years before myopathy diagnosis (cancer history), 10 cancer-free patients followed up for more than 3 years (all statin-naive), and 8 patients without cancer detection but followed up for less than 3 years (statin-exposed, $n=3$ ). Therefore, 12 patients with cancer association (36\%) formed a larger group than that of 7 statin-exposed patients (21\%). Among 12 patients with cancer association, 92\% had cancer detection within 1 year of myopathy diagnosis (after 1.3 years in the remaining patient), 83\% had advanced cancers, and $75 \%$ died of cancers within 2.7 years. Of interest, 1 patient with cancer history had sustained increase in creatine kinase level over 12 years from cancer removal to the development of weakness.

Conclusions: Patients with cancer association formed a large group with poor prognosis in our series of patients with anti-HMGCR Ab+ myopathy. The close synchronous occurrence of cancers and myopathies suggested that cancer association is one of the risk factors for developing anti-HMGCR Ab+ myopathy. Neurol Neuroimmunol Neuroinflamm 2016;3:e290; doi: 10.1212/NXI.0000000000000290

\section{GLOSSARY}

$\mathbf{A b}=$ antibodies; $\mathbf{C A M}=$ cancer-associated myositis; $\mathbf{C l}=$ confidence interval; $\mathbf{C K}=$ creatine kinase; $\mathbf{C S}=$ corticosteroid; DM = dermatomyositis; ENMC = European Neuromuscular Centre; HMGCR Ab = 3-hydroxy-3-methylglutaryl coenzyme A reductase autoantibody; IIM = idiopathic inflammatory myopathy; IVIg = IV immunoglobulin; $\mathbf{M H C}=$ major histocompatibility complex; $\mathbf{m R S}=$ modified Rankin Scale; $\mathbf{M S A}$ = myositis-specific antibody; $\mathbf{M T X}=$ methotrexate; $\mathbf{N} / \mathbf{R}=$ necrotic/regenerating; $\mathbf{N A M}=$ necrotizing autoimmune myopathy; $\mathbf{N S M}=$ nonspecific myositis; $\mathbf{S I R}=$ standardized incidence ratio; $\mathbf{S R P}=$ signal recognition particle.

Idiopathic inflammatory myopathies (IIMs) are characterized by clinical features, myositis-specific antibodies (MSAs), and pathologic findings. Among MSAs, the anti-3-hydroxy-3-methylglutaryl coenzyme A reductase autoantibody (anti-HMGCR Ab) was initially found as an MSA strongly associated with statin exposure. ${ }^{1-3}$ Subsequent studies ${ }^{4-10}$ showed various prevalence rates of statin exposure in anti-HMGCR Ab+ myopathy, which were reportedly low in Asian countries. ${ }^{7,8,10}$ The pathogenesis of anti-HMGCR $\mathrm{Ab}+$ myopathy has been unknown. However, the genetic

From the Department of Neurology and Anti-aging Medicine (M.K., K. Kaida), National Defense Medical College, Saitama; Department of Neurology (A.H., K.T., C.I., N.U., A.K., S.K., S.T., J.S.), Graduate School of Medicine, The University of Tokyo; Department of Neurology (M.H.M., Y.U.), Toranomon Hospital; Division of Rheumatology (Y.M.), Department of Internal Medicine, Showa University School of Medicine, Tokyo; Pulmonary Medicine and Clinical Immunology (K. Kurasawa), Dokkyo Medical University, Tochigi; Department of Diagnostic and Interventional Radiology (H.S.), Osaka City University, Graduate School of Medicine; Department of Neurology (M.S.), Teikyo University School of Medicine; Department of Neurology (A.C.), Kyorin University; Department of Neurology (Y. Shiio), Tokyo Teishin Hospital; Division of Neurology (Y. Sakurai), Mitsui Memorial Hospital, Tokyo; Department of Neurology (T.I.), Tsukazaki Memorial Hospital, Hyogo; and AXA Department of Health and Human Security, Graduate School of Medicine (M.I.), The University of Tokyo, Japan.

Funding information and disclosures are provided at the end of the article. Go to Neurology.org/nn for full disclosure forms. The Article Processing Charge was paid by authors.

This is an open access article distributed under the terms of the Creative Commons Attribution-NonCommercial-NoDerivatives License 4.0 (CC BY-NC-ND), which permits downloading and sharing the work provided it is properly cited. The work cannot be changed in any way or used commercially. 
susceptibility of patients, environmental triggers including statin exposure, or unknown factors have been suggested to be important. ${ }^{11,12}$

Recently, increased risk of cancer in patients with anti-HMGCR $\mathrm{Ab}+$ necrotizing autoimmune myopathy (NAM) has been reported..$^{13}$ There is also a recent report showing a trend toward increased prevalence of anti-HMGCR $\mathrm{Ab}$ among patients with IIM with cancers. ${ }^{9} \mathrm{We}$ also showed in our previous study that antiHMGCR Ab was the second most frequent autoantibody in 75 patients with cancerassociated myositis (CAM).${ }^{14}$ However, in that study, we did not find a significantly increased prevalence rate of anti-HMGCR Ab among patients with CAM, because of a considerable number of cancer-free patients with antiHMGCR Ab + myopathy presumably related to statin exposure or other risk factors, which we did not analyze in that study. Therefore, we considered it important to analyze the clinical courses of patients with anti-HMGCR Ab+ myopathy in relation to statin exposure and cancer development in larger series of patients. Our aim was to show that cancer association becomes a risk factor other than statin exposure for anti-HMGCR Ab+ myopathy.

METHODS Patients. We screened 621 consecutive adult patients with IIM (16 years or older) who were pathologically diagnosed in the University of Tokyo Hospital between 2000 and 2015 and whose serum samples at biopsy were available. In screening, patients with sporadic inclusion body myositis or sarcoid myopathy were excluded on the basis of clinical and pathologic findings. Clinical information was retrospectively analyzed by reviewing the patients' clinical records. The disease onset was defined as the initial awareness of muscular symptoms or the detection of elevated serum creatine kinase (CK) level. The disease duration was defined as the duration between the time of disease onset and muscle biopsy for histopathologic diagnosis.

Definition of the association with cancers. With regard to the association with cancers, we defined patients with cancer association as patients with cancers detected within 3 years of myopathy diagnosis on the basis of commonly used criterion for CAM, ${ }^{15,16}$ and patients with cancer history as patients in whom cancers were detected but more than 3 years before the time of myopathy diagnosis. Among the patients in whom cancers were not detected, we defined cancer-free patients as patients without cancer detection who were followed up for more than 3 years after myopathy diagnosis.

Detection of anti-HMGCR Ab and other MSAs. For the detection of anti-HMGCR Ab, we performed ELISA, as reported elsewhere. ${ }^{14}$ In patients found to be positive by ELISA, we additionally performed Western blot analysis (figure e-1 at Neurology.org/nn). The patients with positive results in both methods were determined to be positive for anti-HMGCR Ab. The patients who were positive for anti-HMGCR $\mathrm{Ab}$ were screened for other MSAs, including anti-Jo-1, anti-PL-7, anti-PL12, and anti-Mi-2 Abs by dot-blot analysis (Diarect AG, Freiburg im Breisgau,Germany), anti-signal recognition particle (SRP) antibodies (Ab) by RNA immunoprecipitation assay (Health Sciences Research Institute, Kanagawa,Japan), and anti-transcriptional intermediary factor $1-\gamma \mathrm{Ab}$ by protein-immunoprecipitation assay. ${ }^{14}$

Histochemical and immunohistochemical evaluations. Cryostat sections of rapidly frozen muscle specimens were processed for routine histochemistry and immunohistochemistry. Anti-human major histocompatibility complex (MHC) Class I/Class II antibodies and anti-C5b-9 antibodies (DAKO, Carpinteria, CA) were used as primary antibodies in immunohistochemical stains. The amount of necrotic/regenerating (N/R) fibers and inflammatory cell infiltration were semiquantitatively estimated: $1=$ absent to mild; $2=$ moderate; 3 = severe. We defined NAM pathology as having the histopathologic findings of $N / R$ fibers $\geq 2$ and inflammatory cell infiltration $\leq 1$ on the basis of the criteria established by the European Neuromuscular Centre (ENMC). ${ }^{17}$ The extent of MHC Class I or Class II antigen expression on non-necrotic fibers (over 25\% of fibers per section) and C5b-9 deposition on sarcolemma (1 or more non-necrotic fibers) were also recorded.

Statistical analysis. A 2-tailed Mann-Whitney $U$ test was performed for different sets of continuous data of clinical features and Fisher exact test was used to compare categorical data. A $p$ value of less than 0.05 was considered to indicate statistical significance. Statistical calculations were performed using JMP Pro 11 (SAS Institute, Cary, NC).

The risk of cancer was estimated by using the standardized incidence ratio (SIR), the ratio of the observed to expected numbers of cancer, and its $95 \%$ confidence interval (CI) assuming that the observed number of cases followed a Poisson distribution. In the present analysis, the observed numbers of cancer were compared with those expected to occur in the general population, adjusted for the same age and sex structure, on the basis of the incidence rates of cancer in 2008 provided by Cancer Registry and Statistics, Cancer Information Service, National Cancer Center, Japan (ganjoho.jp/reg_stat/statistics/dl/index.html). Two types of SIRs were estimated: (1) the SIR of cancers within 3 years of myopathy diagnosis (6 years in total), as reported in a recent study, ${ }^{13}$ where the patients who died, dropped out from follow-up, or had cancer detection during 6 years around myopathy diagnosis were censored at the date of death, last visit, or cancer detection, and the patients with cancers detected more than 3 years before myopathy diagnosis were excluded; and (2) the SIR of cancers within 1 year of myopathy diagnosis ( 2 years in total), using the same methodology.

Standard protocol approvals, registrations, and patient consent. This study was approved by the internal review boards of the University of Tokyo and National Defense Medical College. From each patient, written informed consent was obtained at the time of biopsy and serum sampling.

RESULTS Anti-HMGCR antibodies in patients with IIMs. Thirty-three of 621 sera (5.3\%) from patients with IIMs showed positivity for anti-HMGCR Ab in both ELISA and Western blot analysis (figure e-1).

Characteristics of anti-HMGCR Ab+ myopathy patients in relation to cancers. Table 1 shows clinical and pathologic features of patients with anti-HMGCR $\mathrm{Ab}+$ myopathies. Thirty-three patients with anti-HMGCR $\mathrm{Ab}$ myopathies consisted of 23 women and 10 men. 
The age at disease onset was $59 \pm 15$ years. One woman developed myopathy at 9 months of pregnancy. The associated diseases or factors were as follows: statin exposure ( $\mathrm{n}=7,21 \%)$, rheumatoid arthritis ( $\mathrm{n}=2$, $6 \%$ ), chronic hepatitis $\mathrm{C}$ virus infection $(\mathrm{n}=2,6 \%$ ), cancer association ( $\mathrm{n}=12,36 \%)$, and cancer history $(\mathrm{n}=3,9 \%)$. The statins administered in 7 statinexposed patients were atorvastatin $(\mathrm{n}=3)$, simvastatin $(\mathrm{n}=2)$, pitavastatin $(\mathrm{n}=1)$, and rosuvastatin $(\mathrm{n}=1)$. The average onset age in statin-naive patients $(56 \pm 16$ years) was younger than that in statin-exposed patients $(71 \pm 8$ years $)(p=0.03)$.

On the basis of the ENMC criteria, ${ }^{17} 32$ patients were classified to have NAM ( $\mathrm{n}=21,66 \%$ ), nonspecific myositis (NSM) ( $\mathrm{n}=9,28 \%)$, and dermatomyositis $(\mathrm{DM})(\mathrm{n}=2,6 \%)$. One patient was not classified because the biopsied sample was not suitable for assessment (only fatty tissue was observed).

In relation to cancer, 33 patients were classified as follows: 12 patients with cancer association (36\%), 3 patients with cancer history (9\%), 10 cancer-free patients (30\%), and 8 patients (24\%) without cancers but followed up for less than 3 years. Among them, statin exposure was found in 4 of 12 (33\%) patients with cancer association, 3 of 8 (38\%) patients without cancers but followed up for less than 3 years, and none of the patients was statin-exposed in 3 patients with cancer history and 10 cancer-free patients. Therefore, among 33 patients with anti-HMGCR $\mathrm{Ab}+$ myopathy, the 12 patients with cancer association (36\%) formed a larger group than that of 7 patients with statin exposure $(21 \%)$ in our series ( 4 patients had both cancer association and statin exposure). In comparison of the characteristics between 12 patients with cancer association and 10 cancer-free patients, patients with cancer association were older at onset $(p=0.01)$ with frequent myalgia $(p=0.03)$, higher C-reactive protein levels and erythrocyte sedimentation rate $(p=0.03$ and 0.03$)$, and much higher mortality rate in prognosis $(p<0.001)$ compared with cancer-free patients. In comparison of pathologic findings in relation to cancer association, there were no differences between 12 patients with cancer association and 10 cancer-free patients.

Clinical courses of patients with anti-HMGCR Ab+ myopathy with cancers. Figure 1 (upper half part) shows the follow-up periods of 12 patients with cancer association and 3 patients with cancer history in relation with cancer detection and statin exposure. In 12 patients with cancer association, 92\% (11/12) of the cancers were detected within 1 year of myopathy diagnosis, and the remaining one was detected 1.3 years after myopathy diagnosis. In the analysis of the risk of cancer, the SIR of cancers within 3 years of myopathy diagnosis was 9.1 (95\% CI 4.5-16.2), and that of cancers within 1 year of myopathy diagnosis was 22.1 (95\% CI 10.6-40.7). In 3 patients with cancer history, 2 patients had early colon cancers 11 or 12 years before myopathy diagnosis and 1 patient had lymphoma 7 years before myopathy diagnosis. All 3 patients were followed with no signs of cancer recurrence.

Table 2 shows a summary of the clinical courses of 12 patients with cancer association (patients 1-12) and 3 patients with cancer history (patients 13-15). The 12 patients with cancer association were classified into those with NAM $(\mathrm{n}=8)$, NSM $(\mathrm{n}=3)$, and DM $(\mathrm{n}=1)$. The original cancer sites varied among patients; however, $83 \%(\mathrm{n}=10)$ of the cancers were detected at an advanced stage. Regarding their clinical courses, 9 patients $(75 \%)$ died of cancers between 0.2 and 2.7 years after myopathy diagnosis $(1.2 \pm 1.0$ years, within 1 year in 6 patients).

For the treatment of 12 patients with cancers, 9 patients received anticancer treatments (surgical resection, $\mathrm{n}=5$; chemotherapy, $\mathrm{n}=5$; radiation, $\mathrm{n}=4$; more than one therapy, $n=4$ ) and 3 patients were followed with palliative care. For the treatment of myopathy, oral corticosteroid (CS) was introduced in all 12 patients (40-100 mg/d), in combination with other immunosuppressive or immunomodulating agents in 7 patients (patients 1, 5-7, 9-11) (table 2). Three patients whose cancers were surgically removed and being without relapses at this moment (patients 1-3) achieved normalization of $\mathrm{CK}$ level with improvement of muscle strength at last follow-up. Six patients who died of cancers within 1 year of myopathy diagnosis (patients 4-6, 9-11) showed worsening of general status including muscle strength along with cancer progression and it was difficult to assess the effects of immunotherapy. Three patients who died of cancers more than 2 years after myopathy diagnosis (patients 7, 8, 12) had periods showing decrease in serum CK level and improvement of muscle strength to some extent, however, muscle strength reworsened along with cancer progression.

The 3 patients with cancer history were classified into those with NSM $(n=2)$ and NAM $(n=1)$. Regarding treatments for myopathies, all 3 patients required IV immunoglobulin (IVIg) therapy in addition to other immunosuppressive treatments. At last visit, 2 patients (patients 13, 14) were under good control with normalization of their muscle strength. However, the remaining patient (patient 15) still had severe disability of daily living despite the normalization of CK level at last visit. Of interest, one man (patient 13), in whom increased serum CK level was initially detected at the same time as the surgical removal of colon cancer, showed a sustained increase in $\mathrm{CK}$ level $(>1,000 \mathrm{IU} / \mathrm{L})$ over 12 years. He had been followed up as having idiopathic hyperCKemia until the development of mild weakness in his lower 


\begin{tabular}{|c|c|c|c|c|c|c|}
\hline \multicolumn{7}{|c|}{ Table 1 Clinical and pathologic features of patients with anti-3-hydroxy-3-methylglutaryl coenzyme A reductase autoantibody myopathy } \\
\hline Clinical and pathologic findings & $\begin{array}{l}\text { All patients } \\
(\mathrm{n}=33)\end{array}$ & $\begin{array}{l}\text { Patients with cancer } \\
\text { association }(n=12)^{a}\end{array}$ & $\begin{array}{l}\text { Patients with } \\
\text { cancer history }(n=3)^{b}\end{array}$ & $\begin{array}{l}\text { Cancer-free } \\
\text { patients }(n=10)^{c, d}\end{array}$ & $\begin{array}{l}\text { Patients without cancer } \\
\text { followed }<3 \text { years }(n=8)\end{array}$ & $\begin{array}{l}\text { Patients with cancer association } \\
(n=12) \text { vs cancer-free } \\
\text { patients }(n=10), p \text { value } e^{\text {eff }}\end{array}$ \\
\hline Male:female & 10:23 & $2: 10$ & $2: 1$ & $3: 7$ & 3:5 & 0.62 \\
\hline Age at disease onset, $y$ & $59 \pm 15$ & $65 \pm 12$ & $50 \pm 7$ & $49 \pm 14$ & $68 \pm 16$ & 0.01 \\
\hline \multicolumn{7}{|l|}{ Associated disorders } \\
\hline Cancer & $15 / 33(45)$ & $12 / 12(100)$ & $3 / 3(100)$ & $0 / 10(0)$ & $0 / 8(0)$ & - \\
\hline Within 3 years of myopathy diagnosis & 12/33 (36) & $12 / 12(100)$ & 0/3 (0) & $0 / 10(0)$ & $0 / 8(0)$ & - \\
\hline Statin exposure & $7 / 33(21)$ & 4/12 (33) & $0 / 3(0)$ & $0 / 10(0)$ & 3/8 (38) & 0.10 \\
\hline Collagen disease & 2/33 (6) & $1 / 12(8)$ & $0 / 3(0)$ & $1 / 10(10)$ & $0 / 8(0)$ & 1.00 \\
\hline Chronic hepatitis $\mathrm{C}$ virus infection & 2/33 (6) & 0/12 (0) & $0 / 3(0)$ & $1 / 10(10)$ & 1/8 (13) & 0.45 \\
\hline \multicolumn{7}{|l|}{ Classification by ENMC ${ }^{d}$} \\
\hline Necrotizing autoimmune myopathy & $21 / 32(66)$ & $8 / 12(67)$ & $1 / 3(33)$ & $6 / 9(67)$ & $6 / 8(75)$ & 1.00 \\
\hline Nonspecific myositis & 9/32 (28) & $3 / 12(25)$ & $2 / 3(67)$ & 2/9 (22) & $2 / 8(25)$ & 1.00 \\
\hline Dermatomyositis & 2/32 (6) & $1 / 12(8)$ & $0 / 3(0)$ & $1 / 9(11)$ & $0 / 8(0)$ & 1.00 \\
\hline \multicolumn{7}{|l|}{ Clinical signs and symptoms } \\
\hline Chronic progression (>1 year) & 5/33 (15) & $2 / 12$ (17) & $1 / 3$ (з3) & $2 / 10(20)$ & $0 / 8(0)$ & 1.00 \\
\hline Asymptomatic hyperCKemia (>1 year) & 4/33 (12) & $1 / 12(8)$ & $1 / 3(33)$ & $2 / 10(20)$ & $0 / 8(0)$ & 0.57 \\
\hline Severe muscle weakness (MRC $\leq 3)^{g}$ & $25 / 33(76)$ & 10/12 (83) & $1 / 3(33)$ & $8 / 10(80)$ & $6 / 8(75)$ & 1.00 \\
\hline Myalgia & 14/33 (42) & $7 / 12(58)$ & $1 / 3(33)$ & $1 / 10(10)$ & $5 / 8(63)$ & 0.03 \\
\hline Dysphagia & 8/33 (24) & $5 / 12(42)$ & $0 / 3(0)$ & $1 / 10(10)$ & $2 / 8(25)$ & 0.16 \\
\hline Skin rash ${ }^{\mathrm{h}}$ & 5/33 (15) & $3 / 12(25)$ & $0 / 3(0)$ & $1 / 10(10)$ & $1 / 8(13)$ & 0.59 \\
\hline Arthralgia & 2/33 (6) & $0 / 12(0)$ & $1 / 3(33)$ & $1 / 10(10)$ & $0 / 8(0)$ & 0.45 \\
\hline Interstitial lung disease & 1/33 (3) & 0/12 (0) & $0 / 3(0)$ & $1 / 10(10)$ & $0 / 8(0)$ & 0.45 \\
\hline Modified Rankin Scale & $2.6 \pm 1.0$ & $2.6 \pm 0.8$ & $1.7 \pm 0.6$ & $2.5 \pm 0.8$ & $3.0 \pm 1.2$ & 0.80 \\
\hline \multicolumn{7}{|l|}{ Laboratory data } \\
\hline CK level, IU/L & $9,767 \pm 8,131$ & $12,094 \pm 12,040$ & $11,006 \pm 10,861$ & $8,361 \pm 3,459$ & $7,569 \pm 2,661$ & 0.77 \\
\hline CRP level, mg/dL & $2.1 \pm 5.1$ & $4.2 \pm 7.8$ & $1.2 \pm 2.0$ & $0.1 \pm 0.1$ & $1.9 \pm 3.2$ & 0.03 \\
\hline $\mathrm{ESR}, \mathrm{mm} / \mathrm{h}$ & $28.2 \pm 25.8$ & $38.1 \pm 22.2$ & $14.3 \pm 6.4$ & $15.1 \pm 15.1$ & $39.3 \pm 45.0$ & 0.03 \\
\hline Antinuclear antibodies $(\geq 1: 40)$ & 9/30 (30) & $2 / 10(20)$ & $1 / 3$ (33) & $3 / 10$ (30) & 3/7 (43) & 1.00 \\
\hline Myositis-specific autoantibodies ${ }^{i}$ & 2/33 (6) & 0/12 (0) & 1/3 (33) & $1 / 10(10)$ & $0 / 8(0)$ & 0.45 \\
\hline Mortality rate during follow-up & 9/33 (21) & $9 / 12(75)$ & $0 / 3(0)$ & $0 / 10(0)$ & $0 / 8(0)$ & $<0.001$ \\
\hline
\end{tabular}


Table 1 Continued

\begin{tabular}{|c|c|c|c|c|c|c|}
\hline Clinical and pathologic findings & $\begin{array}{l}\text { All patients } \\
(\mathrm{n}=33)\end{array}$ & $\begin{array}{l}\text { Patients with cancer } \\
\text { association }(n=12)^{a}\end{array}$ & $\begin{array}{l}\text { Patients with } \\
\text { cancer history }(n=3)^{b}\end{array}$ & $\begin{array}{l}\text { Cancer-free } \\
\text { patients }(n=10)^{c, d}\end{array}$ & $\begin{array}{l}\text { Patients without cancer } \\
\text { followed }<3 \text { years }(n=8)\end{array}$ & $\begin{array}{l}\text { Patients with cancer association } \\
(n=12) \text { vs cancer-free } \\
\text { patients }(n=10), p \text { value } e^{\text {eff }}\end{array}$ \\
\hline \multicolumn{7}{|l|}{ Pathologic findings ${ }^{d}$} \\
\hline \multicolumn{7}{|l|}{ N/R fibers } \\
\hline Absent to mild & 1/32 (3) & 1/12 (8) & 0/3 (0) & $0 / 9(0)$ & $0 / 8(0)$ & 1.00 \\
\hline Moderate & 8/32 (25) & $3 / 12$ (25) & 2/3 (67) & 2/9 (22) & $1 / 8(13)$ & 1.00 \\
\hline Severe & 23/32 (72) & $8 / 12(67)$ & 1/3 (33) & $7 / 9$ (78) & $7 / 8$ (88) & 0.66 \\
\hline \multicolumn{7}{|l|}{ Inflammation } \\
\hline Absent to mild & $24 / 32(75)$ & 10/12 (83) & 1/3 (33) & $7 / 9(78)$ & $6 / 8(75)$ & 1.00 \\
\hline Moderate & 6/32 (19) & 1/12 (8) & 2/3 (67) & 2/9 (22) & $1 / 8(13)$ & 0.55 \\
\hline Severe & 2/32 (6) & 1/12 (8) & 0/3 (0) & $0 / 9(0)$ & $1 / 8(13)$ & 1.00 \\
\hline MHC Class I expression & 16/32 (50) & $5 / 12(42)$ & 1/3 (33) & $6 / 9(67)$ & $4 / 8(50)$ & 0.39 \\
\hline MHC Class II expression & O/0 (0) & O/0 (0) & O/0 (0) & O/0 (0) & O/0 (0) & - \\
\hline C5b-9 deposition on sarcolemma & 23/32 (72) & $6 / 12(50)$ & 2/3 (67) & $8 / 9(89)$ & $7 / 8(88)$ & 0.16 \\
\hline
\end{tabular}

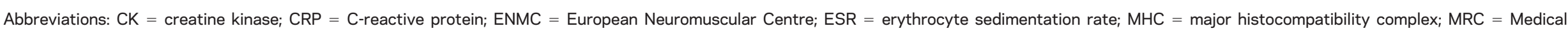
Research Council; N/R fibers = necrotic/regenerating fibers.

Values are mean \pm SD or $n(\%)$.

a Patients with cancer association = patients with cancers detected within 3 years of myopathy diagnosis.

${ }^{\mathrm{b}}$ Patients with cancer history = patients in whom cancers were detected but more than 3 years before the time of myopathy diagnosis.

${ }^{\mathrm{c}}$ Cancer-free patients = patients without cancer detection who were followed up for more than 3 years after myopathy diagnosis.

${ }^{\mathrm{d}}$ One patient was not classified because the biopsied sample was not suitable for assessment (only fatty tissue without muscle fibers).

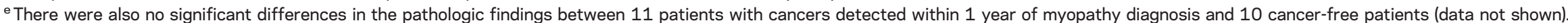

${ }^{\mathrm{f}} \mathrm{A} p$ value of less than 0.05 was considered to indicate statistical significance.

${ }^{9}$ Muscle weakness was proximal dominant and symmetrical in all patients. The weakest muscle strength of the neck or extremities was evaluated.

${ }^{\mathrm{h}}$ Two patients had typical dermatomyositis rash.

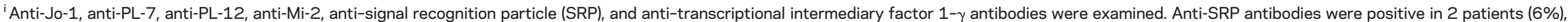
whereas other myositis-specific antibodies were not detected. 
Figure 1 Follow-up periods of 33 anti-3-hydroxy-3-methylglutaryl coenzyme A reductase autoantibody $(\mathrm{HMGCR} A \mathrm{~b}+$ ) myopathy patients in relation to cancer or statin exposure

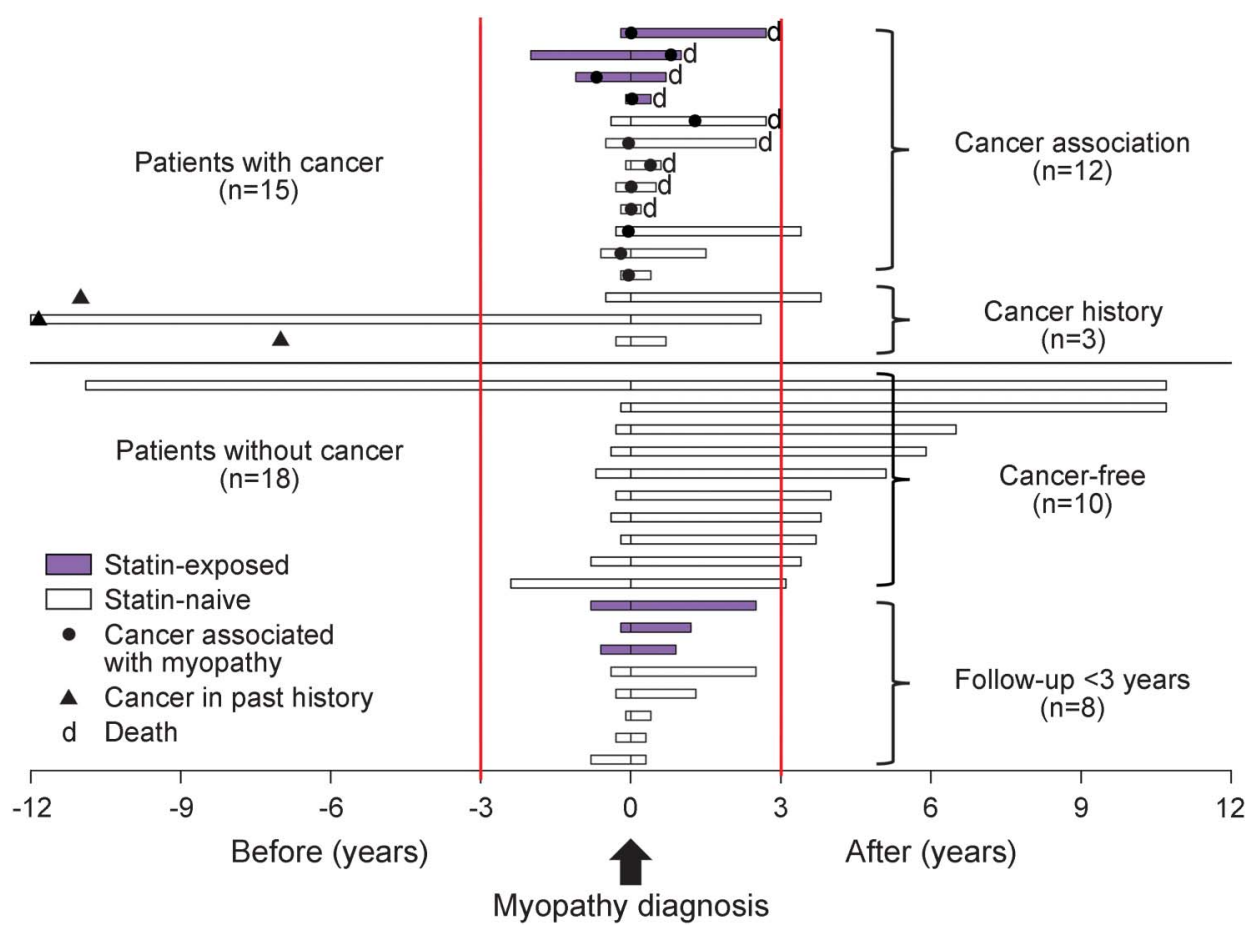

The upper half shows the follow-up periods of 12 patients with cancer association (statin-exposed, $n=4$ ) and 3 patients with cancer history. In 12 patients with cancer association, 92\% (11/12) of the cancers were detected within 1 year of myopathy diagnosis (the remaining one was detected 1.3 years after myopathy diagnosis), and $75 \%(9 / 12)$ died of cancers between 0.2 and 2.7 years after myopathy diagnosis. All 3 patients with cancer history had their cancers treated (closed triangles) and showed no signs of cancer recurrence during follow-up. The lower half shows the follow-up periods of 18 antiHMGCR Ab+ myopathy patients without cancer (statin-exposed, $n=3$ ). Among them, 10 patients were followed up for more than 3 years after myopathy diagnosis and regarded as cancer-free patients. Closed circles = cancers associated with myopathies detected within 3 years of myopathy diagnosis; closed triangles = past cancers detected and treated more than 3 years before myopathy diagnosis with no signs of recurrence in follow-up periods.

limbs. In the remaining 2 patients with cancer history (patients 14, 15), detailed information on their serum CK levels prior to the onset of muscular symptoms was unavailable.

Clinical courses of patients with anti-HMGCR Ab+ myopathy without cancer. Among 18 patients without cancer (figure 1, lower half part), 10 patients were followed up for more than 3 years after myopathy diagnosis $(5.7 \pm 2.9$ years; range $3.1-10.7)$ and regarded as cancer-free.

Table 3 shows a summary of the clinical courses of 10 cancer-free patients. The 10 patients were classified into those with NAM $(n=6), \operatorname{NSM}(n=2)$, $\mathrm{DM}(\mathrm{n}=1)$, and unclassified (fatty tissue, $\mathrm{n}=1)$. All the patients were statin-naive. Although immunotherapy for myopathy was introduced individually by physicians in charge, all but one patient required additional immunosuppressive treatments other than steroids. During clinical courses, immunosuppressants were administered at the initial part of the treatments in combination with steroids in 6 patients (patients 2, 4-6, 9, 10) or at the time of exacerbation in 3 patients (patients 1, 7,8). IVIg therapy was introduced at the initial part of the treatments in 5 patients (patients 1, 2, 8-10) and repeated at the time of exacerbation in 3 patients (patients 8-10). After IVIg therapy, all patients showed improvement of muscle strength and decrease in CK level. At last visit, 10 patients were treated with CS alone $(n=5)$, CS with immunosuppressants (methotrexate [MTX], $\mathrm{n}=3$; azathioprine, $\mathrm{n}=1)$, or MTX alone $(\mathrm{n}=1)$.

At last visit, 5 patients (patients 1-5) showed normalization of CK levels with no significant or slight disability (modified Rankin Scale [mRS] 1 or 2). In contrast, the remaining 5 patients (patients 6-10) showed sustained increase in CK level, including 2 patients (patients 6,7 ) with moderate or moderately severe disability (mRS 3 or 4 ) and increased CK levels. Interestingly, 3 patients (patients 8-10) showed no or slight muscular symptoms (mRS 0 or 1 ) despite markedly increased CK levels at last visits $(2,871 \pm$ 1,152 IU/L; range 1,701-4,004). These 3 patients developed myopathy at relatively younger ages. Although they showed resistance to combined treatments with steroids and immunosuppressants, IVIg 


\begin{tabular}{|c|c|c|c|c|c|c|c|c|c|c|c|c|c|}
\hline Table 2 & Clinical cc & rses of patien & with ar & ti-3-hydroxy-3 & 3-methylglutaryl coenzy & A reductase autoa & antibody & pathy $v$ & h cancer & ssociation or c & ancer history & & \\
\hline \multirow[b]{2}{*}{ Patient } & \multirow[b]{2}{*}{$\begin{array}{l}\text { Onset age, } \\
\text { y/sex }\end{array}$} & \multirow[b]{2}{*}{$\begin{array}{l}\text { Statin } \\
\text { exposure }\end{array}$} & \multirow[b]{2}{*}{$\begin{array}{l}\text { Other } \\
\text { MSAs }\end{array}$} & \multirow[b]{2}{*}{$\begin{array}{l}\text { Classification } \\
\text { by ENMC }\end{array}$} & \multicolumn{2}{|l|}{ Cancer } & \multicolumn{3}{|c|}{ Pretreatment } & \multicolumn{2}{|l|}{ Treatment } & \multirow[b]{2}{*}{$\begin{array}{l}\text { Follow-up } \\
\text { period, } y^{\mathrm{a}}\end{array}$} & \multirow[b]{2}{*}{$\begin{array}{l}\text { Clinical } \\
\text { outcome (mRS) }\end{array}$} \\
\hline & & & & & Site (stage) & $\begin{array}{l}\text { Time between } \\
\text { cancer } \\
\text { and myopathy, y }\end{array}$ & $\begin{array}{l}\text { MRC, } \\
\text { UE/LE }\end{array}$ & $\mathrm{mRS}$ & $\begin{array}{l}\text { CK, } \\
\text { IU/L }\end{array}$ & $\begin{array}{l}\text { Cancer } \\
\text { therapy }\end{array}$ & $\begin{array}{l}\text { Myopathy } \\
\text { therapy }\end{array}$ & & \\
\hline 1 & $34 / \mathrm{M}^{\mathrm{b}}$ & - & - & $\mathrm{DM}$ & $\begin{array}{l}\text { Lymphoepithelial, thyroid } \\
\text { (unclassified) }\end{array}$ & -0.1 & $2 / 3$ & 3 & 46,466 & Surgery, Rad & CS, MP, IVlg & 0.4 & 3 \\
\hline 2 & $77 / F$ & - & - & NSM & Gastric (advanced) & -0.2 & $4 / 3$ & 3 & 5,180 & Surgery & CS & 1.5 & 1 \\
\hline 3 & $78 / F$ & - & - & NSM & Ovary (early) & -0.1 & $4 / 4$ & 2 & 3,831 & Surgery & $\mathrm{CS}$ & 3.4 & 2 \\
\hline 4 & $71 / M$ & - & - & NAM & Gastric (advanced) & \pm 0 & $3 / 3$ & 3 & 18,844 & Chemo & CS & 0.2 & Death \\
\hline 5 & $76 / F$ & Atorvastatin & - & NAM & Gastric (advanced) & \pm 0 & $4 / 3$ & 2 & 5,702 & Palliative care & CS, MTX & 0.4 & Death \\
\hline 6 & $71 / F$ & - & - & NAM & Lung, thymus (advanced) & \pm 0 & $3 / 3$ & 3 & 8,456 & $\begin{array}{l}\text { Surgery, } \\
\text { Chemo, Rad }\end{array}$ & CS, MP, IVlg & 0.5 & Death \\
\hline 7 & $62 / F$ & Simvastatin & - & NAM & Fallopian tube (advanced) & \pm 0 & $4 / 3$ & 4 & 6,715 & $\begin{array}{l}\text { Surgery, } \\
\text { Chemo }\end{array}$ & $\begin{array}{l}\text { CS, MP, IVlg, } \\
\text { MTX }\end{array}$ & 2.7 & Death \\
\hline 8 & $56 / F^{\mathrm{c}}$ & - & - & NAM & $\begin{array}{l}\text { Breast (recurrence) } \\
\text { (advanced) }\end{array}$ & -0.1 & $2 / 3$ & 3 & 6,515 & Chemo, Rad & CS & 2.5 & Death \\
\hline 9 & $61 / F$ & Simvastatin & - & NAM & $\begin{array}{l}\text { Renal pelvis, ureter } \\
\text { (advanced) }\end{array}$ & -0.7 & $3 / 3$ & 3 & 15,970 & Rad & CS, IVlg, MTX & 0.7 & Death \\
\hline 10 & $60 / F$ & - & - & NAM & Renal pelvis (advanced) & +0.4 & $4 / 4$ & 2 & 16,440 & Palliative care & CS, IVCY & 0.6 & Death \\
\hline 11 & $67 / F$ & Atorvastatin & - & NAM & Pancreas (advanced) & +0.8 & $4 / 5-$ & 1 & 2,630 & Palliative care & CS & 1 & Death \\
\hline 12 & $67 / F$ & - & - & NSM & Lung (advanced) & +1.3 & $3 / 3$ & 2 & 8,388 & Chemo & $\begin{array}{l}\text { CS, MP, IVIg, } \\
\text { IVCY, TCR }\end{array}$ & 2.7 & Death \\
\hline 13 & $53 / M^{d}$ & - & SRP & NAM & Colon (early) & -12 & $5-15-$ & 1 & 4,846 & Surgery & CS, IVlg & 2.6 & 1 \\
\hline 14 & $55 / F$ & - & - & NSM & Colon (early) & -11 & $3 / 4$ & 2 & 4,625 & Surgery & CS, IVIg & 3.8 & 0 \\
\hline 15 & $42 / M$ & - & - & NSM & Lymphoma (unclassified) & -7 & $4 / 5-$ & 2 & 23,547 & Chemo & $\begin{array}{l}\text { CS, MP, IVlg, } \\
\text { MTX }\end{array}$ & 0.7 & 5 \\
\hline
\end{tabular}

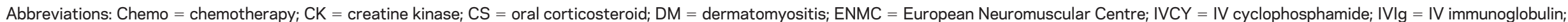

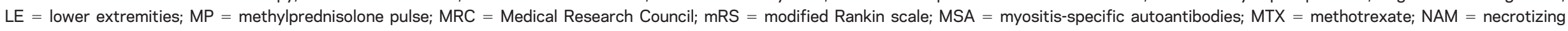
autoimmune myopathy; NSM = nonspecific myositis; PSL = prednisolone; Rad = radiation; SRP = signal recognition particle; TCR = tacrolimus; UE = upper extremities.

${ }^{a}$ The follow-up period was defined as the duration between the time of myopathy diagnosis and the last visit.

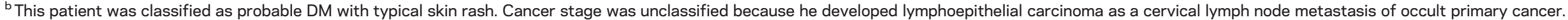

${ }^{\mathrm{c}}$ This patient had multiple metastatic recurrences in lymph nodes, despite surgical removal of primary lesion 3.8 years before myopathy diagnosis.

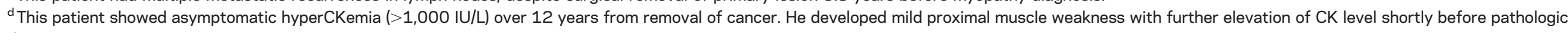
diagnosis. 


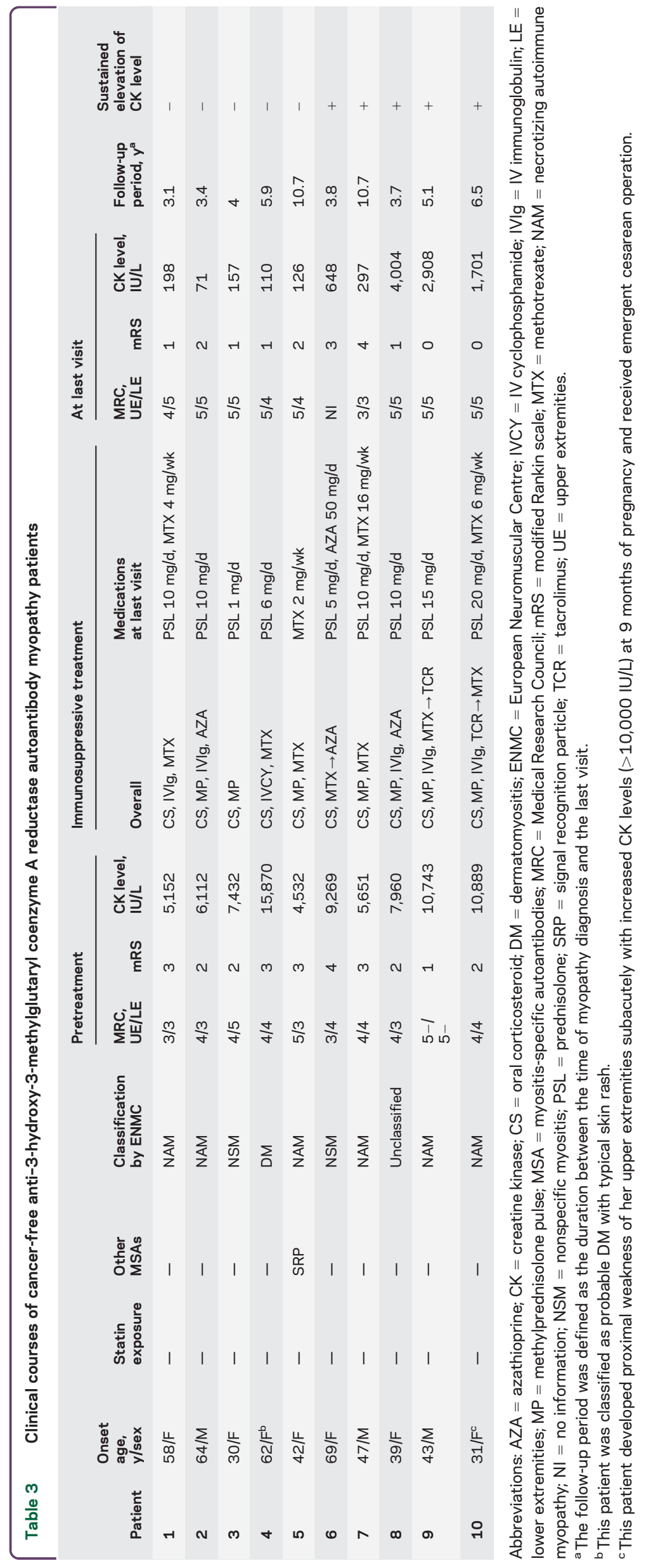

was effective for improving muscle strength and decreasing CK level, which led to clinical remission.

DISCUSSION In this study, to determine whether cancer association becomes a risk factor other than statin exposure for anti-HMGCR Ab+ myopathy, we analyzed the clinical courses including the presence of statin exposure and the development of cancer in 33 patients with anti-HMGCR Ab+ myopathy, whom we identified among 621 patients with IIM (33/621, 5.3\%).

We found that the prevalence rate of cancer detection within 3 years of myopathy diagnosis (cancer association) among patients with anti-HMGCR $\mathrm{Ab}+$ myopathy was $36 \%(12 / 33)$, which was higher than that of statin exposure (21\%) (4 patients had both cancer association and statin exposure). In 12 patients with cancer association, the associated cancers were detected mostly (92\%) within 1 year of myopathy diagnosis and frequently (83\%) at an advanced stage. In addition, $67 \%(8 / 12)$ of our patients were not exposed to statins. In analysis of cancer risk, the SIR of cancers in patients with anti-HMGCR $\mathrm{Ab}+$ myopathy was extremely high within 1 year of myopathy diagnosis.

In previous large-scale studies, the prevalence rates of cancers in patients with anti-HMGCR Ab+ myopathy ranged from $4 \%$ to $26 \%$ (irrespective of the temporal association between cancer detection and myopathy diagnosis). ${ }^{1,4,5,8-10}$ In this study, the prevalence rate of cancer association in patients with anti-HMGCR Ab + myopathy is higher than those in previous reports. However, considering the close temporal association between cancer detection and myopathy diagnosis, extremely increased risk of cancer within 1 year of myopathy diagnosis, and the frequent association of the myopathy with cancer in an advanced stage, there should be some biological link between cancer association and anti-HMGCR $\mathrm{Ab}+$ myopathy development.

Regarding the pathogenesis of anti-HMGCR $\mathrm{Ab}+$ myopathy, it has been suggested that the genetic susceptibility of patients and environmental triggers including statin exposure or unknown factors in statin-naive patients would be pathogenesis-relevant factors. ${ }^{11,12}$ Taking these into consideration together with the finding that two-thirds of the patients were statin-naive, cancer is a factor closely associated with anti-HMGCR $\mathrm{Ab}+$ myopathy development in our 12 patients. The difference in the prevalence rate of cancer association between our series and previous reports may be attributable to differences in genetic background and the intensity of cancer screening in patients.

Recently, in the NAM subset of IIMs, it has been reported that the frequency of cancer association is 
increased in MSA-negative NAM and anti-HMGCR $\mathrm{Ab}+\mathrm{NAM}$ than in anti-SRP Ab+ NAM. ${ }^{13}$ In comparison with the previous study, our study is different in that we showed cancer association in anti-HMGCR $\mathrm{Ab}+$ myopathy, not limited to NAM subsets of IIMs. Indeed, in our 12 patients with cancer association, 4 patients with non-NAM subsets of IIMs were included (NSM, $\mathrm{n}=3$; DM, $\mathrm{n}=1$ ). Our study shows the association between cancer and anti-HMGCR $\mathrm{Ab}+$ myopathy regardless of pathologic subtypes. Considering the close synchronous occurrence of cancers and myopathies in our 12 patients (the detection of cancer was confined within 1.3 years of myopathy diagnosis), along with the finding that there were no patients with cancers detected after 3 years of myopathy diagnosis, cancer association is at least one of the factors that triggered anti-HMGCR Ab+ myopathy.

Notably, one man with cancer history, who was dual positive for anti-HMGCR $\mathrm{Ab}$ and anti-SRP $\mathrm{Ab}$ as reported elsewhere, ${ }^{10,18,19}$ showed a sustained increase in CK level over 12 years from cancer removal to the development of symptomatic myopathy shortly before pathologic diagnosis (figure 1). The clinical course of this patient is similar to that of statin-exposed patients who tolerated statin exposure for a long duration before the development of symptomatic myopathy. ${ }^{11}$ In our patient, it would be likely that the autoimmune processes initially started, triggered by cancer, and he tolerated it for 12 years until some additional unknown factors induced the development of symptomatic myopathy.

The low prevalence rate of statin-exposed patients in anti-HMGCR $\mathrm{Ab}+$ myopathy in Asian countries is already reported. ${ }^{7,8,10}$ In our series, all 10 cancer-free patients were statin-naive, which suggested that there were unknown risk factors for developing antiHMGCR Ab + myopathy other than cancer association or statin exposure. In addition, interestingly, 3 cancerfree patients showed full or almost full recovery of muscle strength despite markedly elevated CK levels. Similar clinical courses have been reported in both statinexposed and statin-naive patients. ${ }^{1,3,20,21}$ A sustained increase in CK levels with mild weakness in these patients including our 3 patients supports the suggestion that development of symptomatic myopathy requires additional unknown factors including environmental triggers, ${ }^{21}$ which remain to be elucidated.

Mechanisms underlying anti-HMGCR $\mathrm{Ab}+$ myopathy remain unknown, and only statin, genetic susceptibility, environmental triggers, or both have been suggested. ${ }^{12}$ In this study, we found cancer association was more frequent than statin exposure in our cohort, and most of the associated cancers were in an advanced stage and were detected within 1 year of myopathy diagnosis. Our findings suggest that cancer association is one of the risk factors for the development of anti-HMGCR Ab+ myopathy.

\section{AUTHOR CONTRIBUTIONS}

Dr. Kadoya contributed to evaluation of the patients, acquisition of data, analysis and interpretation, and preparation of the manuscript. Dr. Kaida contributed to analysis and interpretation, study supervision, and revision of the manuscript. Dr. Shimizu contributed to study concept and design, data acquisition, analysis and interpretation, and critical revision of the manuscript for important intellectual content. Drs. Taira, Ikenaga, Uchio, Hida, Kubota, Miwa, Kurasawa, Shimada, Sonoo, Chiba, Shiio, Uesaka, Sakurai, and Izumi contributed to acquisition of data. Dr. Maeda contributed to study supervision and revision of the manuscript. Dr. Inoue contributed to analysis and interpretation. Drs. Kwak and Tsuji contributed to study concept and designs, study supervision, and revision of the manuscript.

\section{ACKNOWLEDGMENT}

The authors thank Drs. Hiroo Ichikawa, Hidetomo Murakami, Takahiro Tokunaga, Kazuhiro Itaya (Showa University School of Medicine), Ayumi Uchibori (Kyorin University), Naohisa Ueda (Yokohama City University Medical Center), and Minako Yamada (Omori Red Cross Hospital) for help with the patient follow-up, and Michiko Sagishima, Naoko Tokimura, and Masako Nishizawa for technical assistance.

\section{STUDY FUNDING}

No targeted funding.

\section{DISCLOSURE}

M. Kadoya and A. Hida report no disclosures. M. Maeda received research support from JSPS KAKENHI. K. Taira, C. Ikenaga, N. Uchio, A. Kubota, K. Kaida, Y. Miwa, and K. Kurasawa report no disclosures. H. Shimada received research support from Grants-in-Aid for Scientific Research. M. Sonoo served on the Editorial Board for Muscle and Nerve, Clinical Neurophysiology Practice, Clinical Neurology, and Japanese Journal of Clinical Neurophysiology, and received research support from Grants-inAid for Scientific Research from the Ministry of Education, Science, Sports and Culture of Japan, Ministry of Health, Labour and Welfare of Japan. A. Chiba and Y. Shiio report no disclosures. Y. Uesaka served on the speaker's bureau for Bayer Yakuhin Ltd., Pfizer Seiyaku K.K., Boehringer Ingelheim Japan, Inc., Otsuka Pharmaceutical Co., Ltd., Sanofi K.K., Bristol-Myers-Squibb Co., Mitsubishi Tanabe Pharma Co., and Glaxo SmithKline K.K., and received research support from MHLW of Japan. Y. Sakurai and T. Izumi report no disclosures. M. Inoue is editor-in-chief of Journal of Epidemiology, section editor for $B M C$ Cancer, and receives a financial contribution from the AXA Research Fund as chair holder of the AXA Department of Health and Human Security, University of Tokyo. S. Kwak consulted for Gene Therapy Research Institution, Co., Ltd., served on the speaker's bureau for Institute of Biomedical Research and Innovation, and received research support from Japan Society for the Promotion of Science, AMED, Japan ALS Association. S. Tsuji received travel funding and/or speaker honoraria from Kowa Pharmaceuticals Co. Ltd., Japan Blood Productions Organization, Mitsubishi Tanable Pharma Co., Bayer Japan, Janssen Pharmaceutical K.K., Genzyme Japan K.K., Eisai Co. Ltd., FP_Pharmaceutical Co., Dainippon Sumitomo Pharma Co. Ltd., Otsuka Pharmaceutical Co. Ltd., Actelion Pharmaceuticals Japan Ltd., Sony Corporation, Nikkei Business Publications Inc., and Leave a Nest Co. Ltd., served as editor-in-chief for Neurology ${ }^{\circledR}$ and Clinical Neuroscience, and received research support from Sanofi K.K., Japan Blood Products Organization, Mitsubishi Tanabe Pharma Co., Pfizer Japan Inc., Ono Pharmaceutical Co. Ltd., Daiichi Sankyo Co. Ltd., Eisai Co. Ltd., Kowa Pharmaceutical Co. Ltd., GlaxoSmithKline K.K., The Ministry of Education, Culture, Sports, Science and Technology of Japan, and Japan Agency for Medical Research and Development. J. Shimizu received research support from JSPS KAKENHI, Health and Labour Sciences Research Grants from the Ministry of Health, Labour and Welfare of Japan, and Intramural Research Grant for Neurological and Psychiatric Disorders of NCNP. Go to Neurology.org/nn for full disclosure forms.

Received July 28, 2016. Accepted in final form August 26, 2016. 


\section{REFERENCES}

1. Christopher-Stine L, Casciola-Rosen LA, Hong G, Chung T, Corse AM, Mammen AL. A novel autoantibody recognizing $200-\mathrm{kd}$ and 100-kd proteins is associated with an immunemediated necrotizing myopathy. Arthritis Rheum 2010;62: 2757-2766.

2. Mammen AL, Chung T, Christopher-Stine L, et al. Autoantibodies against 3-hydroxy-3-methylglutaryl-coenzyme A reductase in patients with statin-associated autoimmune myopathy. Arthritis Rheum 2011;63:713-721.

3. Werner JL, Christopher-Stine L, Ghazarian SR, et al. Antibody levels correlate with creatine kinase levels and strength in anti-3-hydroxy-3-methylglutaryl-coenzyme A reductaseassociated autoimmune myopathy. Arthritis Rheum 2012 64:4087-4093.

4. Allenbach Y, Drouot L, Rigolet A, et al. Anti-HMGCR autoantibodies in European patients with autoimmune necrotizing myopathies: inconstant exposure to statin. Medicine 2014;93:150-157.

5. Alshehri A, Choksi R, Bucelli R, Pestronk A. Myopathy with anti-HMGCR antibodies: perimysium and myofiber pathology. Neurol Neuroimmunol Neuroinflamm 2015; 2:e124.

6. Klein M, Mann $\mathrm{H}$, Pleštilová $\mathrm{L}$, et al. Increasing incidence of immune-mediated necrotizing myopathy: single-centre experience. Rheumatology 2015;54:2010-2014.

7. Watanabe Y, Suzuki S, Nishimura H, et al. Statins and myotoxic effects associated with anti-3-hydroxy-3-methylglutarylcoenzyme A reductase autoantibodies: an observational study in Japan. Medicine 2015;94:e416.

8. Ge Y, Lu X, Peng Q, Shu X, Wang G. Clinical characteristics of anti-3-hydroxy-3-methylglutaryl coenzyme A reductase antibodies in Chinese patients with idiopathic inflammatory myopathies. PLoS One 2015;10:e0141616.

9. Limaye V, Bundell C, Hollingsworth $\mathrm{P}$, et al. Clinical and genetic associations of autoantibodies to 3-hydroxy-3-methylglutaryl-coenzyme A reductase in patients with immunemediated myositis and necrotizing myopathy. Muscle Nerve 2015;52:196-203.

10. Watanabe Y, Uruha A, Suzuki S, et al. Clinical features and prognosis in anti-SRP and anti-HMGCR necrotising myopathy. J Neurol Neurosurg Psychiatry 2016;87:10381044.

11. Babu S, Li Y. Statin induced necrotizing autoimmune myopathy. J Neurol Sci 2015;351:13-17.

12. Mammen AL. Statin-associated autoimmune myopathy. N Engl J Med 2016;374:664-669.

13. Allenbach Y, Keraen J, Bouvier AM, et al. High risk of cancer in autoimmune necrotizing myopathies: usefulness of myositis specific antibody. Brain 2016;139:2131-2135.

14. Hida A, Yamashita T, Hosono Y, et al. Anti-TIF1- $\gamma$-antibody and cancer-associated myositis: a clinicohistopathologic study. Neurology 2016;87:299-308.

15. Troyanov Y, Targoff IN, Tremblay JL, Goulet JR, Raymond Y, Senecal JL. Novel classification of idiopathic inflammatory myopathies based on overlap syndrome features and autoantibodies: analysis of 100 French Canadian patients. Medicine 2005;84: 231-249.

16. Chinoy H, Fertig N, Oddis CV, Ollier WE, Cooper RG. The diagnostic utility of myositis autoantibody testing for predicting the risk of cancer-associated myositis. Ann Rheum Dis 2007;66:1345-1349.

17. Hoogendijk JE, Amato AA, Lecky BR, et al. 119th ENMC international workshop: trial design in adult idiopathic inflammatory myopathies, with the exception of inclusion body myositis, 10-12 October 2003, Naarden, The Netherlands. Neuromuscul Disord 2004;14: 337-345.

18. Kassardjian CD, Lennon VA, Alfugham NB, Mahler M, Milone M. Clinical features and treatment outcomes of necrotizing autoimmune myopathy. JAMA Neurol 2015; 72:996-1003.

19. Suzuki S, Nishikawa A, Kuwana M, et al. Inflammatory myopathy with anti-signal recognition particle antibodies: case series of 100 patients. Orphanet J Rare Dis 2015;10:61.

20. Grable-Esposito P, Katzberg HD, Greenberg SA, Srinivasan J, Katz J, Amato AA. Immune-mediated necrotizing myopathy associated with statins. Muscle Nerve 2010;41: 185-190.

21. Mammen AL, Taniakou E. Intravenous immune globulin for statin-triggered autoimmune myopathy. N Engl J Med 2015;373:1680-1682. 


\section{Neurology \\ Neuroimmunology \& Neuroinflammation}

\section{Cancer association as a risk factor for anti-HMGCR antibody-positive myopathy Masato Kadoya, Ayumi Hida, Meiko Hashimoto Maeda, et al. \\ Neurol Neuroimmunol Neuroinflamm 2016;3; \\ DOI 10.1212/NXI.0000000000000290}

This information is current as of October 7, 2016

\section{Updated Information \& Services \\ Supplementary Material}

References

Citations

Subspecialty Collections

Permissions \& Licensing

Reprints including high resolution figures, can be found at: http://nn.neurology.org/content/3/6/e290.full.html

Supplementary material can be found at: http://nn.neurology.org/content/suppl/2016/10/07/3.6.e290.DC1

This article cites 21 articles, 2 of which you can access for free at: http://nn.neurology.org/content/3/6/e290.full.html\#\#ref-list-1

This article has been cited by 1 HighWire-hosted articles: http://nn.neurology.org/content/3/6/e290.full.html\#\#otherarticles

This article, along with others on similar topics, appears in the following collection(s):

Autoimmune diseases

http://nn.neurology.org//cgi/collection/autoimmune_diseases Muscle disease

http://nn.neurology.org//cgi/collection/muscle_disease

Information about reproducing this article in parts (figures,tables) or in its entirety can be found online at:

http://nn.neurology.org/misc/about.xhtml\#permissions

Information about ordering reprints can be found online: http://nn.neurology.org/misc/addir.xhtml\#reprintsus

Neurol Neuroimmunol Neuroinflamm is an official journal of the American Academy of Neurology.

Published since April 2014, it is an open-access, online-only, continuous publication journal. Copyright $\odot$ 2016 American Academy of Neurology. All rights reserved. Online ISSN: 2332-7812.

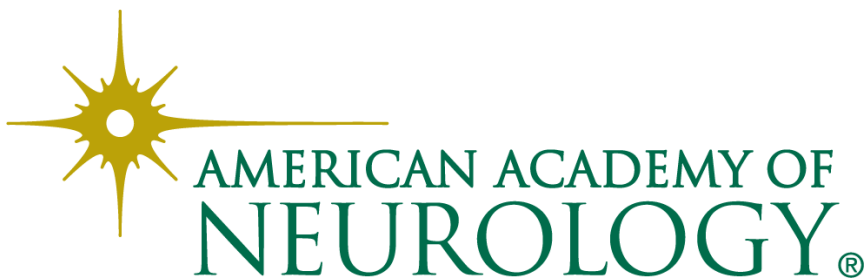

